\title{
NOTAS SOBRE EL PATRIMONIO DE UN LINAJE TRUJILLANO A FINES DEL SIGLO XV. EL CASO DE LOS TAPIA
}

\author{
Antonio González Gómez \\ Universidad de Sevilla
}

Con motivo de mis trabajos de investigación en Jerez de la Frontera, referentes al ámbito andaluz bajomedieval, he encontrado un fondo documental, relativamente valioso, sobre un cierto número de familias trujiIlanas en el Archivo de la Marquesa de Campo Real (1). Esta documentación entró a formar parte en el siglo XVII (2) del vínculo del linaje jerezano de los Zurita, poseedores del título de marqués. La existencia de estos legajos ha permanecido inédita. Unicamente en 1922, el presbitero, Clodoaldo Naranjo Alonso, por su amistad personal con el entonces marqués de Campo Real, tuvo la oportunidad de consultar documentos exclusivamente genealógicos para la realización de la historia de "Trujillo y su tierra" (3).

Dicha documentación nos revela un fenómeno interesante: la difusión y vulgarización de las estructuras familiares de la alta nobleza entre los miembros de la caballería. A lo largo del siglo XV aparece una serie de familias trujillanas - Bonilleja, Tapia, Altamirano, Pizarro, etc.-que detentan las formas clásicas de mantener riqueza: tierras, edificios, ganaderia, ajuares...

Sin embargo esta acumulación de bienes se veía constreñida por las fórmulas de sucesión. Todos los componentes de la familia heredan. Como consecuencia de esta costumbre testamentaria, la.relativa fragmentación y dispersión de los bienes impedian una concentración del poder económico y social. Para evitar esta situación surge desde finales del siglo XV un movimiento cuya finalidad es el cerramiento y jerarquización interna de los cuadros familiares a través de la creación de vínculos y mayorazgos. 
Esta circunstancia trasluce la adquisición por las capas de la caballería, que vive en las ciudades, de los modos de pensamiento, acción y organización de la alta nobleza, de los grandes, es decir, la asunción por parte de los caballeros de la estructura familiar de los grandes linajes nobiliarios, constituidos en vínculos ordenados que permitan la transmisión y conservación del poder mediante la práctica de matrimonios endógamos y la fundación de mayorazgos que posibilitan la transmisión hereditaria de bienes, responsabilidades y honores entre los hijos varones primogénitos. De esta manera se crea también entre los representantes de los caballeros una pequeña nobleza de linaje patrilineales.

Este es el caso de la familia Tapia. La documentación nos permite calibrar estos fenómenos en un ejemplo concreto, examinando la fortuna de dicho linaje trujillano durante el siglo XV, comprobando los lazos de parentesco y las alianzas matrimoniales existentes dentro de un mismo grupo social. Por último, podremos observar la movilidad de los bienes de una generación a otra y en el interior de los miembros de una misma familia.

El fondo documental está integrado por testamentos, inventarios, compraventas... realizados por una familia patronímica: Ios Tapia desde la segunda mitad del siglo XV hasta mediados del siglo XVI. El linaje se consolida en tiempos de Gómez de Tapia (fallecido en 1489) por su matrimonio con Francisca de las Cabezas, hija de García González de Gironda (o de las Cabezas) y por la herencia recibida de Mencia González, hermana del anterior y esposa de Juan de Hinojosa. Todos aparecen avecindados en Trujillo. La familia Tapia pertenecía a la pequeña oligarquia urbana de caballeros al senvicio de la alta nobleza, concretamente de los condes de Belalcázar, como criados y contadores mayores (4).

La hacienda de Gómez de Tapia recogió gran parte de los bienes de su suegro, García González de Gironda. Por esta razón se conserva en el fondo documental del linaje el testamento y el inventario de éste. García González de Gironda realizó su testamento en Trujillo, el día 8 de octubre de 1458 (5). Era hijo de Gómez Núñez de Gironda. Estipulaba las características mandas piadosas: ser enterrado en la iglesia de San Miguel con sus treintanarios correspondientes a cargo del cabildo de clérigos de la ciudad y ofrenda anuales, conceder 10 maravedies para la obra de la citada iglesia, entregar una blanca a todas las iglesias de Trujillo y del arrabal con sus ermitas (6), idéntica cantidad también para la obra de Santa Maria de Plasencia, a los lacerados de Plasencia y Béjar, etc. Después ordena que su mujer, Catalina González, herede toda la parte e derecho que yo he en Gironda, término de esta cibdad, ansi de herencia que yo ove y heredé de Juan Gil, fijo de Lázaro Gómez, como de mi padre, como de compra, con el molino que es en la dicha heredad e todo lo de las puertas adentro de las casas... de la dicha aldea de Gironda".

Esta cláusula obedecía a la intención de Garcia González de Gironda de recompensar a su mujer, Catalina González, por las propiedades de su 
esposa que él había vendido y entregado en casamiento a mis fijas. La misma finalidad tiene la donación en herencia a su mujer de unas casas en Trujillo y una viña en Santa Cruz de la Sierra. Todo ello con la condición que dichos bienes, después de la muerte de doña Catalina González, tornen... a mis herederos. Por último estipula que su hija Mencia reciba 50.000 maravedies para igualarla con los que llevaron en casamiento sus otras fijas y nombra como albaceas y testamentarios a su hermano, Juan de las Cabezas y a su mujer, Catalina González.

Según el testamento, el matrimonio García González de Gironda-Catalina González tuvo cuatro hijas: María Jiménez, Juana Sánchez, Francisca de las Cabezas y Mencia González.

Un porcentaje importante de la fortuna reunida por García González de Gironda se debió como indica su propio testamento a la herencia recibida de su primo hermano, Juan Gil. Este redactó su testamento en Trujillo, el día 9 de abril de 1427 (7). En primer lugar dispone que sea enterrado en el cementerio de la iglesia de Santa María de Trujillo con sus misas y ofrendas anuales más las limosnas acostumbradas a las restantes iglesias de la ciudad, de su arrabal y ermitas, a la obra de Santa Maria de Plasencia, a los lacerados de Béjar, a la Trinidad, Cruzada y Santa Olalla de Barcelona. A continuación consigna que su mujer, Constanza Fernández, reciba las casas en las que moró como enmienda de ciertos bienes que troxo al casamiento más treinta cabeças de ganado que troxo cuando casó, las quales yo vendi para mi mantenimiento e suyo. A renglón seguido manda que a su primo, Garcia González de Gironda, le sea entregada toda la parte y derecho que el testador tenía en la horden e heredat que dicen el Aldehuela de Diego Gómez y en Gironda, ambas posesiones en el término de Trujillo, que le pertenecian por herencia de su padre, Lázaro Gómez. Estos bienes le serán entregados a García González de Gironda cuando cumpla una condición: la de dar 30 cabezas de ganado a su mujer, Constanza Fernández.

A este conjunto de propiedades heredadas hay que añadir toda la parte y derecho que el mencionado Juan Gil tenía sobre una viña, Ilamada de La Planta, en Santa Cruz de la Sierra con la parte que tengo en una casa y en un lagar en el dicho lugar, que en un principio asignó a su hermano, Fernando Gómez, a quien concedió 200 maravedies en otra manda testamentaria, en enmienda de ciertos bienes que yo vendi e fincaron de Garcia, mi hermano. Sin embargo, precisa más adelante, que si su hermano Fernando Gómez no quisiera esta viña, la reciba su primo Garcia González de Gironda, dándole éste a cambio el dinero que montó mis rentas que García, mi hermano, avía en Centenera, que vendi a Alfón Garcia Calderón. Por último, manda a su primo que venda todos mis puercos y bueyes y faga cantar por mi ánima un treintenario cerrado y le designa su heredero.

Por tanto, como resultado de una doble herencia: la del matrimonio Juan Gil-Constanza Fernández, sus primos, y la de su padre, Gómez 
Núñez de Gironda; de la aportación de bienes de la dote de su mujer, Catalina González y de seis compraventas, García González de Gironda reunió un patrimonio relativamente importante. Dicho patrimonio puede conocerse gracias a un inventario de sus bienes, leído en Trujillo, el día 3 de enero de 1460 (8), por Antonio González, escribano público de la ciudad por el prior y fryales e convento del monasterio de Santa María de Guadalupe... ante Juan López del Arroyo, pesquisidor y juez por el rey en Trujillo. Fue presentado por Catalina González, como testamentaria de su marido. Los bienes que integraban la hacienda eran los siguientes:

\section{a) Bienes rústicos}

La heredad de Gironda. En ella poseía cinco partes. Una procedía de la herencia de su padre, Gómez Núñez de Gironda, otra de su primo, Juan Gil, y la tercera, de la parte y derecho que ovo de los fijos de Gómez Núñez de Gironda, la cual pertenecía completamente a su mujer, Catalina González, por haber vendido el marido un pedazo de tierra que ella poseía en la aldea del Becerro. Las otras dos partes provenían de compraventas. La primera efectuada a los hijos de Francisco Gil de Maria y la segunda a Alfonso de Gironda y a García Arazo. La propiedad de estas dos partes estaban repartidas al 50 por ciento entre ambos cónyuges. No obstante el inventario no proporciona datos sobre la superficie ni sobre la cuantía de las adquisiciones.

La heredad de Atalayuela. En ella poseía una parte y derecho comprada a Sancho Fierro cuya mitad correspondía a su mujer.

La heredad de Carmonilla. Tenía en ella 2 yugadas, de tierra que fueron compradas a Fernando Blázquez de Roanes en 1449 por 2.500 maravedíes con la finalidad de concentrar sus tierras en torno a la heredad de Gironda, colindante con Carmonilla (9). La mitad también era propiedad de Catalina González.

Una viña en Santa Cruz de la Sierra, llamada de La Planta, con una casa y bodega, procedente de la herencia de su primo, Juan Gil.

\section{b) Bienes urbanos}

Las casas de la calle Olleros en Trujillo fueron adquiridas a los testamentarios de María Sánchez, vecina de Trujillo, mujer de Marcos Sánchez, recuero, difunto, los cuales para cumplir su testamento vendieron en 1455 a García González de Gironda unas casas que la dicha Maria Sánchez avia y dexó al tiempo de su finamiento con un corral que está a las espaldas de las dichas casas que son en la calle que dicen de Olleros que son en el arenal de Truxillo, por 5.600 maravedíes con cargo de pagar un tributo de 100 maravedies y un par de gallinas a Pascuala García (10). 


\section{c) Bienes semovientes}

La cabaña ganadera estaba integrada por 100 cabeças de vacas e bueyes grandes e chicos; 60 cabeças de puercos machos e fembras grandes e chicas; 40 ovejas, 2 yeguas, 1 potro y una potranca. De las 203 cabezas del ganado, la mitad correspondía a Catalina González.

Sin embargo no aparece reseñada en el inventario la cuarta parte de la heredad de Aldehuela, llamada Sevillaga, en término de Trujillo que fue adquirida por García González de Gironda en 1449 a Blasco Domínguez Pixoto por 10.000 maravedíes (11).

En resumen, la formación de este patrimonio se debió a cinco herencias (tres partes de la heredad de Gironda, la viña de La Planta y la Aldehuela de Diego Gómez) y a seis compraventas (cinco de tierras: dos en Gironda, una en Atalayuela, otra en Carmonilla, otra en Aldehuela, y una de una casa en Trujillo) (Gráfico $n^{\circ} 1$ ).

Gráfico $N^{\circ}{ }^{\circ} 1$

BIENES DE GARCIA GONZALEZ DE GIRONDA (?-1458)

\begin{tabular}{l|l|l}
\hline \multicolumn{1}{c}{ Naturaleza } & Término & \multicolumn{1}{c}{ Observaciones } \\
\hline $\begin{array}{l}\text { Cinco partes de la heredad } \\
\text { de Gironda }\end{array}$ & Trujillo & $\begin{array}{l}\text { Tres partes provenian de heren- } \\
\text { cia y dos de compraventas }\end{array}$ \\
\hline $\begin{array}{l}\text { Una parte de la heredad de la } \\
\text { Atalayuela }\end{array}$ & Trujillo & Compra \\
\hline $\begin{array}{l}\text { La parte de la heredad de la } \\
\text { Aldehuela de Diego Gómez }\end{array}$ & Trujillo & Herencia de Juan Gil \\
\hline $\begin{array}{l}\text { La cuarta parte de la heredad } \\
\text { de la Aldehuela llamada Se- } \\
\text { villaga }\end{array}$ & Trujillo & Compra en 1449 \\
\hline $\begin{array}{l}2 \text { yugadas de tierra en la he- } \\
\text { redad de Carmonilla }\end{array}$ & Trujillo & Compra en 1449 \\
\hline $\begin{array}{l}\text { Viña la Planta en el ejido de } \\
\text { Santa Cruz de la Sierra }\end{array}$ & Trujillo & Herencia de Juan Gil \\
\hline Casas de la calle Olleros & Trujillo & Compra en 1455 \\
\hline $\begin{array}{l}100 \text { vacas y bueyes } \\
60 \text { puercos }\end{array}$ & & \\
\hline
\end{tabular}




\begin{tabular}{l|l|l}
\hline \multicolumn{1}{|c|}{ Naturaleza } & Término & Observaciones \\
\hline 40 ovejas & & \\
\hline 2 yeguas & & \\
\hline 1 potro & & \\
\hline 1 potranca & & \\
\hline
\end{tabular}

Una vez viuda Catalina González, la hacienda fue aumentada por dos nuevas adquisiciones cuya política era la concentración geográfica de propiedades agrícolas. La primera compraventa tuvo lugar en Trujillo, el día 16 de octubre de 1469. Isabel García, mujer de Juan de las Cabezas, difunto y cuñado de Catalina González, le vendía a ésta por juro de heredat... toda la parte e derecho que yo e Alfonso Cabeças e Gonzalo e Gómez e Maria Ximénez e Juan Sánchez, mis fixos... hemos en la aldea e heredad de Gironda... con sus casas e casares e cercas e cortinales e tierras de pasto e de pan levar e con aguas por 21.000 maravedies (12).

La segunda adquisición se realizó en Trujillo, el día 24 de marzo de 1474. Lorenzo de la Jara, vecino de esa ciudad, en nombre de su mujer y de Isabel García, su cuñada, mujer del difunto Diego Gómez, vendía a Catalina González toda la parte e derecho que teniamos en la heredad de Torresyllas, en término de Truxillo, asi de tierras de pasto común como de pan llevar e la lavor e de casas e casares e cercas e cortinales por el precio de 5.000 maravedies. La posesión de la propiedad se llevó a cabo el día 6 de abril de 1474 poniendo los pies en una casa de la aldea de Torresyllas con su corral que estaba delante (13).

Este conjunto de bienes pasará íntegramente a la familia de los Tapia a través del matrimonio entre Francisca de las Cabezas, hija de Gonzalo García de Gironda, y Gómez de Tapia. La primera circunstancia que incrementará el patrimonio de cónyuges será la muerte de Mencia González, hermana de Francisca, en cuyo testamento deja por herederos de la dehesa de Gironda a los hijos de ésta (14). Por este motivo, el día 13 de noviembre de 1476, el criado de Francisca de las Cabezas, Pedro Arias, toma posesión de dicha propiedad en su nombre (15). Operación que vuelve a repetirse el 23 de noviembre de ese mismo año ante la oposición mostrada por Tomé Gil, sobrino de Mencia González. Sin embargo por orden de la justicia de Trujillo y de su alguacil, Alfonso de Miranda, los hijos de Gómez de Tapia y de su mujer son entregados en la tenencia y posesión de todos los bienes raíces e muebles que fueron de Mencia González, mujer de Juan de Hinojosa y de Teresa, su hija, difunta.

Después de indicar los bienes que componian su ajuar, se toma posesión de la parte de la heredad de Gironda y el día 25 del mismo mes de la 
heredad de Aldehuela de Blasco Domínguez, colocando el procurador de Gómez de Tapia, Pedro Gallego, ciertas piedras sobre la pared de un huerto (16).

No obstante el 13 de octubre de 1480 , a causa de esta herencia, vuelve a efectuarse una partición de la heredad de Gironda entre el matrimonio Tapia y Juan de Hinojosa, por una parte, y por otra, sus cuñados, Pedro Jiménez Barrantes y María Jiménez. Dividieron la heredad en dos partes y las echan a suerte. El escribano hizo dos escriptos pequeños en papel cada uno. A continuación los puso en dos pellicas de cera redondas. Hecho el sorteo copieron las dichas suertas de la manera siguiente: A Gómez de Tapia y a su mujer, Francisca de las Cabezas, y a Juan de Hinojosa, su cuñado, la suerte de la casa con la cocina, la torre y la delantera de la casa de Gironda. A Pedro Jiménez Barrantes y a María Jiménez, mujer Alvar Alfonso, también sus cuñados, la parte de la dehesa vieja y Navalagrulla con los dos tercios de los Girondos, el molino y el palacio con los corrales. Al mismo tiempo se precisa que en el caso de poseer ejido la heredad los derechos a su aprovechamiento se dilucidirán en otro acuerdo entre ambas partes (17).

Se concluye este episodio en ese mismo año de 1480 . El día 31 de diciembre, Fernando Alonso y Francisco Rodríguez, clérigos, como jueces y árbitros entre Gómez de Tapia y Juan de Hinojosa, esposo de Mencia González, emiten una sentencia sobre la hacienda de Gironda, que pertenecía a su suegro, García González de Gironda. Por ella, Juan de Hinojosa obtenia de las cinco partes de Giroda litigadas, dos, y las otras tres restantes eran para Gómez de Tapia (18).

El mencionado Gómez de Tapia, hijo de Alonso de Tapia, formaba parte, como ya hemos indicado, de la pequeña oligarquía urbana de Trujillo, donde estaba avecindada la familia, lo cual no era impedimiento para servir a los Sotomayor, condes de Belalzázar, como criados y contadores mayores. Así Gómez de Tapia se dirige a la villa de Belalcázar en 1487 para servir a Teresa Enríquez, condesa de la mencionada villa, viuda del conde Gutierre de Sotomayor. Antes de iniciar su viaje redacta su primer testamento en Gironda, el día 15 de octubre de 1487, donde manda que si muere en Balalcázar mis señores me entierren en el monasterio del señor San Francisco de la Columpna y si ocurre en Trujillo entonces en la iglesia de Santiago. Reparte una serie de limosnas entre sus criados y designa a sus hijos como herederos (19).

Un año después, Gómez de Tapia se encuentra en Valladolid. En esta localidad efectuó su segundo y último testamento, el dia 4 de febrero de 1488. En él modifica el lugar de su enterramiento. Ahora alige el monasterio de San Francisco de Trujillo con sus misas correspondientes. Ordena dar 5 maravedies cada día a las emparedadas para que rueguen por su alma y vuelve a nombrar herederos a sus hijos (20).

Muere Gómez de Tapia entre el 12 de diciembre de 1488, fecha en la que recibe una donación, y el 22 de agosto de 1489, día en el que se 
escribe el testamento de su hijo, Alonso de Tapia y en el que aparece ya difunto.

A través de una serie de circunstancias fortuitas: herencias de parientes y de un beneficioso matrimonio, Gómez de Tapia recibe una considerable y fragmentada porción de una propiedad: la dehesa o heredad de Gironda. Este hecho fue valorado por el mismo Gómez de Tapia, como lo prueba que las dos únicas compraventas que efectuara tuvieran por objeto la ampliación de la citada propiedad. Efectivamente, en Trujillo, el día 13 de agosto de 1487, adquirió a Mayor Garcia, beata del monasterio de beatas cerca de la iglesia de Santa María de esa ciudad, hija de García de Araxo, toda la parte e derecho que Maria de Dios, mi tia y beata, me mandó por mi vida en la parte y derecho que mi tía tenia en la heredad que dicen Gironda... en la suerte que dicen de los Girondos, menos una parte que entrega a Juana de Gironda, su prima y también beata, hija de Alonso de Gironda, en compensación y como equivalencia de la parte de la heredad de Torreherrera que ésta le dio. La cuantía de la venta se elevó a 3.000 maravedíes (21).

La segunda compraventa tuvo lugar en Trujillo, el día 11 de abril de 1488. En ella Catalina de Gironda, mujer de Juan Calderón y Gómez Nuño, hijo de Fernando de Gironda, vecinos de Trujillo y én nombre igualmente de Juan, hermano de ambos, vendieron a Gómez de Tapia por 3.500 maravedies las dos tercias partes de toda la parte e derecho que nosotros avemos en la heredad... de Gironda, que heredaron de María de Dios, beata, su tía (22).

Para concluir, la hacienda de Gómez de Tapia se vio favorecida por las donaciones de Teresa de Cristo, beata y religiosa en el monasterio de las beatas, cercano a la iglesia de Santa María de Trujillo, tía de su mujer, Francisca de las Cabezas. Así, el día 15 de noviembre de 1485 le hizo donación a su sobrina de toda la parte y derecho que poseía sobre la heredad y dehesa de Noderuela, que era la cuarta parte de toda la heredad... con todas sus casas e casares e cercas e corrales e cortinales e ejidos e tierras e prados de pasto e pan llevar. Tomó posesión de ella Gómez de Tapia, el día 26 de noviembre de 1485. La recorrió a pie, cavó la tierra en algunos sitios y cortó ciertas ramas de un carrasco (23). Esta donación, como la siguiente, efectuada el 12 de diciembre de 1488, obedecía a los buenos servicios recibidos del matrimonio Gómez de TapiaFrancisca de las Cabezas. Por esta razón, le dona todos sus bienes raíces, muebles y semovientes (24) sin especificarlos en la carta de donación.

Con este patrimonio reunido se aprecia la toma de conciencia de la adscripción a un estado noble. Fenómeno social que se evidencia en el testamento de Alonso de Tapia, hijo de Gómez de Tapia, quien encontrándose en Belalcázar al servicio de la condesa Teresa Enriquez, su señora, y estando muy fatigado de dolencias y enfermedad, concede el 22 de agosto de 1489 poder a su madre y a Pedro Gallego, criado y mayordomo de la citada condesa, para que redacten su testamento. En él se 
establece que sus bienes quedarán en su linaje, tronco, solar y apellido (25).

Sin embargo esta disposición mental y económica no se tradujo en la obtención de un vínculo o mayorazgo. De ahí que el patrimonio se viera en cada generación sometido a un proceso de dispersión y fragmentación entre los miembros de la propia familia. Los únicos medios para contrarrestar ese hecho eran acudir a la práctica de una política matrimonial cuidadosamente meditada, y de adquisiciones de propiedades.

Esta característica social se constata magníficamente en el reparto de los bienes de Gómez de Tapia y de su mujer entre sus herederos en 1507. Por dicho documento nos es factible conocer las propiedades rurales y urbanas que poseía el matrimonio en el momento de su muerte y la distribución posterior de estos entre sus cuatro hijos: Juana López de Tapia, Juan de Tapia, Garcia de Tapia y Gómez de Tapia, sobrino de los anteriores e hijo del difunto, Alonso de Tapia. El patrimonio de los Tapia en 1507 (26) era el siguiente:

\section{a) Bienes rústicos}

Estaban integrados por siete heredades o dehesas, cuatro viñas, dos perales, dos cercas, una huerta y unos casares.

Las heredades eran las de Palazuelo, Agudo del Castillo, Aldehuela de Blasco Domínguez, del Corral, Gironda, Aguijón de Carmonilla, la suerte de las Dehesillas y Torrecillas, todas en el término de Trujillo.

Las cuatro viñas estaban en el ejido de Santa Cruz de la Sierra: una suerte de viñas Ilamada Cigontal, la viña del Canchón, de La Planta y de la Higuera.

Los dos perales estaban junto a la suerte de viñas del Cigontal en Santa Cruz de la Sierra.

Las dos cercas también se localizaban en el ejido de Santa Cruz de la Sierra.

La huerta de la Longuera situada junto a un arroyo en el ejido de Danta Cruz de la Sierra.

Los casares se encontraban en la calle Garguera.

b) Bienes urbanos

Estaban compuestos por las casas principales de Santa Cruz de la Sierra y las casas de Trujillo donde vivian sus padres.

c) Otros bienes

Tenían 3.000 maravedies de juro y 700 maravedies de hierba creciendo y menguando de suelo e propiedad e señorio en la heredad de El Toril. 
Con respecto al inventario realizado en 1460 de las propiedades del matrimonio García González de Gironda-Catalina González, esta partición de bienes efectuadas en 1507 no indica las heredades siguientes: Atalayuela, la Aldehuela de Diego Gómez, la cuarta parte de la misma Aldehuela llamada Sevillaga, la casa de la calle Olleros de Trujillo y el ganado. En cambio son citadas por primera vez las 11 partes de la heredad de Palazuelo, la cuarta parte de la heredad de Agudo del Castillo, la heredad del Corral, la heredad del Aguijón de Carmonilla, la suerte de las Dehesillas también en Carmonilia y la suerte de Torrecillas, las viñas del Cigontal, Cachón y de la Figuera en el ejido de Santa Cruz de la Sierra, la huerta de La Longuera y dos perales en el mismo lugar, los casares de Garguera, las dos cercas y las casas principales de Santa Cruz de la Sierra, las casas principales de Trujillo, 3.000 maravedies de juro y 700 maravedíes de renta de la hierba en la heredad del Toril. Continúa reseñandose en la partición de 1507 las heredades de la Aldehuela de Blasco Domínguez y Gironda y la viña de La Planta en el ejido de Santa Cruz de la Sierra. Tampoco aparece mencionada en el citado reparto la heredad de Torrecilla, adquirida en 1474, y la de Noderuela, donada en 1485.

Pues bien, estos bienes en 1507 fueron distribuidos entre sus hijos de la siguiente manera. Juana López de Tapia recibió el 81,81 por ciento de la heredad de Palazuelo (27), la suerte de viña llamada Cigontal en el ejido de Santa Cruz de la Sierra, dos perales en el mismo lugar, la huerta de La Longuera también en la misma localidad, la cuarta parte de las casas principales de Santa Cruz de la Sierra y el 25 por ciento de 3.000 maravedíes de juro. (Gráfico $\mathrm{n}^{\circ} 2$ ).

Gráfico N. 2

BIENES DEL MATRIMONIO GOMEZ DE TAPIA-FRANCISCA DE LAS CABEZAS (1460-1507)

\begin{tabular}{l|l|l}
\hline \multicolumn{1}{c|}{ Naturaleza } & Término & Partición en el año 1507 \\
\hline $\begin{array}{l}\text { Once partes de la heredad de } \\
\text { Palazuelo }\end{array}$ & Trujillo & $\begin{array}{l}\text { Nueve partes de Juana López de } \\
\text { Tapia y dos de Juan de Tapia }\end{array}$ \\
\hline $\begin{array}{l}\text { La cuarta parte.de la heredad } \\
\text { de Agudo del Castillo }\end{array}$ & Trujillo & Juan de Tapia \\
\hline $\begin{array}{l}\text { Toda la parte y derecho de la } \\
\text { Aldehuela de Blasco Domin- } \\
\text { guez }\end{array}$ & Trujillo & Juan de Tapia \\
\hline $\begin{array}{l}\text { Toda la parte y derecho de la } \\
\text { heredad del Corral }\end{array}$ & Trujillo & Juan de Tapia \\
\end{tabular}




\begin{tabular}{|c|c|c|}
\hline Naturaleza & Terminu & Particion en el año $150^{\circ}$ \\
\hline $\begin{array}{l}\text { Cinco partes de la heredad } \\
\text { de Gironda }\end{array}$ & Trujillo & $\begin{array}{l}\text { El } 91 \% \text { de Garcia de Tapia y } \\
\text { Gómez de Tapia; el } 9 \% \text { de Juan } \\
\text { de Tapia }\end{array}$ \\
\hline $\begin{array}{l}\text { La heredad del Aguijón de } \\
\text { Carmonilla }\end{array}$ & Trujillo & $\begin{array}{l}\text { Pro indiviso entre García de Ta- } \\
\text { pia y Gómez de Tapia }\end{array}$ \\
\hline $\begin{array}{l}\text { Suerte de las Dehesillas en } \\
\text { Carmonilla }\end{array}$ & Trujillo & $\begin{array}{l}\text { Pro indiviso entre Garcia de Ta- } \\
\text { pia y Gómez de Tapia }\end{array}$ \\
\hline La suerte de Torrecilla & Trujillo & $\begin{array}{l}\text { Pro indiviso entre Garcia de Ta- } \\
\text { pia y Gómez de Tapia }\end{array}$ \\
\hline $\begin{array}{l}\text { La suerte de viñas del Ci- } \\
\text { gontal en el ejido de Santa } \\
\text { Cruz de la Sierra }\end{array}$ & Trujillo & Juana López de Tapia \\
\hline $\begin{array}{l}\text { La viña del Canchón en el } \\
\text { ejido de Santa Cruz de la } \\
\text { Sierra }\end{array}$ & Trujillo & Juan de Tapia \\
\hline $\begin{array}{l}\text { La suerte de viña de la Planta } \\
\text { en el ejido de Santa Cruz de } \\
\text { la Sierra }\end{array}$ & Trujillo & García de Tapia \\
\hline $\begin{array}{l}\text { La suerte de viña de la Hi- } \\
\text { guera en el ejido de Santa } \\
\text { Cruz de la Sierra }\end{array}$ & Trujillo & Gómez de Tapia \\
\hline $\begin{array}{l}\text { Dos perales en el ejido de } \\
\text { Santa Cruz de la Sierra }\end{array}$ & Trujillo & Juana López de Tapia \\
\hline $\begin{array}{l}\text { La huerta de La Longuera en } \\
\text { el ejido de Santa Cruz de la } \\
\text { Sierra }\end{array}$ & Trujitlo & Juana López de Tapia \\
\hline $\begin{array}{l}\text { Los casares de la calle de } \\
\text { Carguera (Santa Cruz de la } \\
\text { Sierra) }\end{array}$ & Trujillo & $\begin{array}{l}\text { Juan de Tapia y García de Tapia, } \\
\text { el } 25 \% \text {; el } 50 \% \text {. Gómez de Tapia }\end{array}$ \\
\hline $\begin{array}{l}\text { Dos cercas en Santa Cruz de } \\
\text { la Sierra }\end{array}$ & Trujillo & $\begin{array}{l}\text { Una era completamente de Gó- } \\
\text { mez de Tapia; otra, de Juan de } \\
\text { Tapia y Garcia de Tapia, ambos } \\
\text { con el } 25 \% \text { cada uno, y el } 50 \% \\
\text { restante, de Gómez de Tapia }\end{array}$ \\
\hline
\end{tabular}




\begin{tabular}{l|l|l}
\hline \multicolumn{1}{c|}{ Naturaleza } & Termino & \multicolumn{1}{c}{ Particion en el año 1507 } \\
\hline $\begin{array}{l}\text { Las casas principales de } \\
\text { Santa Cruz de la Sierra }\end{array}$ & Trujillo & $\begin{array}{l}\text { Juana López de Tapia (25\%), } \\
\text { Garcia de Tapia (25\%) y Gómez } \\
\text { de Tapia (50\%) }\end{array}$ \\
\hline $\begin{array}{l}\text { Las casas principales de } \\
\text { Trujillo }\end{array}$ & Trujillo & $\begin{array}{l}\text { Garcia de Tapia (75\%) y Gómez } \\
\text { de Tapia (25\%) }\end{array}$ \\
$\begin{array}{l}3.000 \text { maravedies de juro } \\
700 \text { maravedies de renta de } \\
\text { hierba en laheredad del Toril }\end{array}$ & Trujillo & $\begin{array}{l}\text { El 25\% cada uno de los 3 hijos y } \\
\text { el nieto, Gómez de Tapia }\end{array}$ \\
\hline
\end{tabular}

Juan de Tapia heredó el 18,18 por ciento de la dehesa o heredad de Palazuelo (28), la cuarta parte de la heredad de Agudo del Castillo, toda la parte de la heredad de Aldehuela de Blasco Domínguez, toda la parte de la heredad del Corral, el 9 por ciento de la heredad de Gironda sin casas, casares, cerca, corral y huerto, aunque sí 17,5 maravedies de renta de hierba (29), la viña del Canchón en Santa Cruz de la Sierra, la cuarta parte del Alcacer y de la cerca que está a la carrera, 400 maravedies de renta de hierba en la dehesa del Toril (30) y el 25 por ciento de los 3.000 maravedies de juro.

García de Tapia y su sobrino Gómez de Tapia obtenían pro indiviso el 91 por ciento de la heredad de Gironda con todas sus instalaciones, edificios y rentas (31), la heredad del Aguijón de Carmonilla, la suerte de las Dehesillas en Carmonilla y la suerte de Torrecillas.

García de Tapia, por su parte, poseía la suerte de viña de La Planta en el ejido de Santa Cruz de la Sierra, la cuarta parte de los casares de la calle de Garguera, la cuarta parte de la cerca (32), las tres cuartas partes de las casas principales de Trujillo y la cuarta parte de las otras casas principales de Santa Cruz de la Sierra, además del correspondiente 25 por ciento de los 3.000 maravedíes de juro.

Gómez de Tapia recibía la suerte de viñas de la Higuera en Santa Cruz de la Sierra, la mitad de los casares de la calle Garguera, el 50 por ciento de la cerca (33), toda la cerca llamada La Gorrona en el ejido de Santa Cruz de la Sierra, la cuarta parte de las casas de Trujillo y las dos cuartas partes de las casas principales de Santa Cruz de la Sierra, aparte de los 750 maravedies correspondientes de los 3.000 de juro.

De esta relación puede observarse los efectos sucesorios en la fragmentación y distribución de las tierras y demás bienes entre los miembros 
de la familia. Todos los hijos reciben heredades. Cada una de las cuatro viñas de Santa Cruz de la Sierra son repartidas entre los tres hijos y el nieto de Gómez de Tapia, al igual que los 3.000 maravedíes de juro. Las casas principales de Santa Cruz de la Sierra son divididas entre Juana López de Tapia (25\%), Garcia de Tapia (25\%) y Gómez de Tapia (50\%) y las de Trujillo entre García de Tapia (75\%) y Gómez de Tapia (25\%). Juan de Tapia es el único hijo que no hereda bienes urbanos y Juana López de Tapia tampoco recibe casares y cercas. Al mismo procedimiento se recurre para el reparto de los casares de la calle Garguet (Juan de Tapia, el $25 \%$; García de Tapia el $25 \%$ y Gómez de Tapia el $50 \%$ ) y la cerca en las mismas proporciones.

Esta partición de los bienes de Gómez de Tapia realizada en 1507 abarcó también los bienes muebles, raíces y semovientes que quedaron e fincaron... de Mencia Gónzalez, los cuales no se especifican ni aparecen repartidos.

De los cuatro hijos de Gómez de Tapia, la documentación sólo hace referencia a García de Tapia por su matrimonio con María Altamirano. Aparece al año siguiente de la muerte de su padre en 1490 efectuando una adquisición de tierras. Realizó ocho compraventas entre 1490 y 1536 . Ello supuso el desembolso de 78.900 maravedíes. El objeto de tales transacciones fue la posesión de tierras en las heredades de Carrascalejo y Gironda, un pedazo de viña en Robledo, el censo de unas casas en Trujillo, parte de un molino y dos casas en Garciaz.

Garcia de Tapia, avecindado en Trujillo en las casas principales de su padre, Gómez de Tapia, amplió y concentró mediante tres adquisiciones el núcleo de propiedades que había recibido de su padre: la heredad de Gironda y la suerte de Torrecillas. Efectivamente el 18 de septiembre de 1490 compró a su tía, María Jiménez, vecina de Trujillo, toda la parte y derecho que ésta tenía en la heredad de Carrascalejo, término de Trujillo, por 12.000 maravedies (34). El 28 de julio de 1500 volvió a comprar otra parte de la heredad de Carrascalejo, colindante con la heredad de Gironda, por 14.000 maravedíes, en esta ocasión a Juan de Nimegra y a su mujer, Francisca Jiménez, vecinos de Trujillo (35). Y en el lugar del Puerto, el día 3 de febrero de 1513, adquirió a Maria Aguilar, hija de Gonzalo de Aguilar y mujer de Francisco de las Casas, vecina de Trujillo, toda la cuarta parte y derecho que ésta tenia en la heredad de Gironda heredada de María Jiménez (36) con sus pastos y abrevaderos por 29.000 maravedies (37).

También Garcia de Tapia compró una viña en Garciaz, lugar de TrujiIIo. El 27 de mayo de 1500 Alonso Serrano y su mujer, Juana García, vecinos de la citada localidad, le vendieron una viña en el Robledo en donde dicen La Citolilla por 17.000 maravedíes (38).

Las otras cuatro compraventas comprenden dos casas y un molino en Garciaz y un censo en Trujillo. En el lugar de Garciaz, el día 19 de abril de 
1496 compró a Bartolomé Moreno, vecino de esa población, toda la parte e derecho del molino que heredé de mi padre que es de seis partes, una. Se encontraba en la ribera de Garciaz cerca de los huertos del concejo. La cuantía se elevó a 2.000 maravedíes (39). En 1501, Francisco Castellano, vecino de Garciaz, vendió al honrado García de Tapia, una casa en la plaza de ese lugar que fueron de sus padres por 2.700 maravedies (40). En la misma localidad adquirió a Inés González, mujer de Juan Vizcaino, vecina de Garciaz, el día 19 de julio de 1529, una casa por 2.200 maravedíes (41). Por último, el 18 de noviembre de 1536 compró al monasterio de San Francisco de la Puerta de Coria de Trujillo 60 maravedíes de renta de censo perpetuo que tenía la comunidad sobre las casas principales de García de Tapia cercanas a la iglesia de la Veracruz. Fueron vendidas por 1.500 maravedíes (42). Con ello concluía la posesión absoluta de su morada en Trujillo, pues previamente el dia 11 de diciembre de 1510 habia realizado un trueque con su sobrino Gómez de Tapia. García de Tapia entregaba la cuarta parte que le correspondía de las casas principales de Santa Cruz de la Sierra por la partición de los bienes de su padre, efectuada en 1507, a Gómez de Tapia, mientras éste a su vez le daba la cuarta parte de las citadas casas principales de Trujillo (43).

En 1519 partió con su sobrino, Gómez de Tapia, el indiviso que poseían ambos sobre la heredad de Gironda. García de Tapia y Luis de Comargo, mercader, vecino de Trujillo, como procurador de Gómez de Tapia, pidieron al alcalde mayor de la ciudad, Francisco de León, se designara dos partidores que dividieran la tierra de Gironda. Los tres designaron a García Jiménez, vecino de Santa Cruz de la Sierra, y a Sancho Solano, vecino del Puerto. Ambos hicieron el 26 de agosto de ese año 25 partes, todas agrupadas. García de Tapia recibió 13 y Gómez de Tapia, 12. Partición y adjudicación confirmada por Diego García Carrasco, morador en Torrecillas, como tercer partidor.

El 9 de septiembre, a los doce días siguientes, Alonso Casco y Diego de Orellana, alarifes y vecinos de Trujillo, dividieron la torre, casas, corrales, colgadizos, caballerizas, establos, casares, pajar, horno y gallinero de Gironda. García de Tapia recibió la casa principal con la parte de corral correspondiente, colgadizo, casares, pajar y horno. Gómez de Tapia obtuvo la parte de la torre, caballeriza y corral.

También se repartió la suerte de Torrecillas y un huerto de la heredad de Gironda. A García de Tapia le correspondió la suerte de Torrecillas y la licencia de que su ganado, para ir a beber, pudiera transitar por ella hasta el Aguijoncillo, desde mayo hasta San Miguel. El huerto de Gironda con la parte del pozo pertenecería a Garcia de Tapia y la parte próxima al arroyo a Gómez de Tapia (44) (Gráfico $n^{\circ} 3$ ).

El patrimonio de bienes reunidos por García de Tapia le permitió conceder a sus hijas importantes dotes. Asi en el 28 de septiembre de 1541, Hernando Calderón, marido de Francisca de Tapia, hija de Garcia de Tapia, vecina de Trujillo, expresa que su padre le dio en dote y casamiento 
Gráfico N ${ }^{\circ} 3$

BIENES DE GARCIA DE TAPIA (1507-1547)

\begin{tabular}{|c|c|c|}
\hline Naturaleza & Término & Observaciones \\
\hline $\begin{array}{l}14 \text { partes de la heredad de } \\
\text { Gironda }\end{array}$ & Trujillo & $\begin{array}{l}\text { Trece de herencia y una parte de } \\
\text { compra en } 1513\end{array}$ \\
\hline $\begin{array}{l}\text { La heredad del Aguijón de } \\
\text { Carmonilla }\end{array}$ & Trujillo & $\begin{array}{l}\text { Indiviso con su sobrino Gómez } \\
\text { de Tapia }\end{array}$ \\
\hline $\begin{array}{l}\text { Parte de la heredad de } \mathrm{Ca}- \\
\text { rrascalejo }\end{array}$ & Trujillo & Adquiridas en 1490 y 1500 \\
\hline $\begin{array}{l}\text { La suerte de las Dehesillas en } \\
\text { Carmonilla }\end{array}$ & Trujillo & Indiviso con Gómez de Tapia \\
\hline La suerte de Torrecilla & Trujillo & Indiviso con Gómez de Tapia \\
\hline $\begin{array}{l}\text { Viña de la Planta en el ejido } \\
\text { de Santa Cruz de la Sierra }\end{array}$ & Trujillo & Herencia \\
\hline $\begin{array}{l}\text { Viña en el Robledo, llamada } \\
\text { la Citolilla, en Garciaz }\end{array}$ & Trujillo & Compra en 1500 \\
\hline 1 molino en Garciaz & Trujillo & Compra en 1496 \\
\hline $\begin{array}{l}\text { El } 25 \% \text { de los casares de la } \\
\text { calle de Garguera (Santa } \\
\text { Cruz de la Sierra) }\end{array}$ & Trujillo & Herencia \\
\hline $\begin{array}{l}\text { El } 25 \% \text { de una cerca en Santa } \\
\text { Cruz de la Sierra }\end{array}$ & Trujillo & Herencia \\
\hline 2 casas en Garciaz & Trujillo & Compras en 1501 y 1529 \\
\hline Casas principales en Trujillo & Trujillo & Herencia \\
\hline 750 maravedíes de juro & & Herencia \\
\hline Ganado sin especificar & & \\
\hline
\end{tabular}


10.000 maravedies de renta de hierba situados y señalados en la heredad de Gironda... y ciento e ochenta ovejas mayores y diez puercas mayores $y$ una vaca y un ajuar y casa alahajada; bienes en los que se incluía su legítima. El matrimonio renuncia por ello a todo derecho a la herencia de García de Tapia (45).

El día 22 de agosto de 1540 redacta en Trujillo su testamento, María Altamirano, mujer de García de Tapia. Estipula ser enterrada en la iglesia de la Veracruz en la sepultura de sus padres. Tras ordenar las mandas piadosas y retribuir los buenos servicios de su criada y esclavos (46), nombra herederos de sus bienes gananciales y dotales a sus dos hijos, Alonso de Tapia y Juan Altamirano, salvo que la parte que yo tengo en la heredad de Valbuitrero lo aya $y$ eréde de mejora... Juan Altamirano, mi hijo, por su necesidad de ser coxo, aparte de su legítima integrada por casas, viñas y molinos en Garciaz (47).

García de Tapia escribió su testamento en Trujillo, el 2 de abril de 1547. Manda que los cofrades de la Cruz y la cofradía del Espíritu Santo le entierren en la iglesia de Santiago. Dispone misas para los parientes difuntos, entre ellos su hijo Juan Altamirano y su sobrino, Gómez de Tapia. Manda cancelar las deudas con Diego Mitrado, vecino de Santa Cruz de la Sierra, su porquero. Estipula las dotes que concedió a sus dos hijas cuando entraron en el monasterio de la Puerta de Coria, Ana Altamirano y Juana de Tapia. Designa como heredero a su hijo, Alonso de Tapia (48).

Precisamente este Alonso de Tapia conseguirá por real facultad de 1559 fundar el vínculo o mayorazgo en favor de su hijo, Garcia de Tapia, el dia 14 de abril de 1561. Los bienes dotales procedian de las herencias y compras efectuadas por sus antepasados (49).

Por tanto, los bienes agrarios constituyeron la base económica del patrimonio de los Tapia. Sin embargo, hasta la creaçión del mayorazgo en 1561 , esta riqueza se vio sometida por los efectos de sucesión hereditaria a una constante fragmentación entre los miembros de la propia familia. Pero en el caso de los Tapia este fenómeno se vio compensado por las aportaciones de propiedades de otras herencias o donaciones de parientes y por una posterior política de adquisiciones. En efecto Gómez de Tapia, esposo de Francisca de las Cabezas, contempló cómo su patrimonio se beneficiaba de las propiedades heredadas de su suegro, García González de Gironda, de de su cuñada, Mencia González, así como de las donadas por Teresa de Cristo, tía de su mujer. Este hecho se observa perfectamente en el caso de la heredad de Gironda, que pasó al patrimonio de los Tapia a través de Francisca de las Cabezas, quien la heredó de su padre, García González de Gironda. Sin embargo, en 1507, tras el fallecimiento del matrimonio Gómez de Tapia-Francisca de las Cabezas, Gironda es repartida entre sus hijos, Garcia de Tapia y Juan de Tapia, y su nieto, Gómez de Tapia. El primero y el último recibieron pro indiviso el 91 por ciento de la heredad. Juan de Tapia obtuvo el 9 por ciento. Se había 
repartido una propiedad, reunida gracias a las herencias testamentarias de ciertos parientes y a las compraventas efectuadas a los miembros de dos familias: Ios Gironda a Alfonso de Gironda y a su hermano, García Araxo. Posteriormente, en 1487, Mayor García, hija de Garcia Araxo, vendió otra parte de la citada propiedad. En 1488, Catalina de Gironda recibe 3.500 maravedies por la venta de sus dos terceras partes. En los restantes casos los vendedores son los propios miembros de la familia. Así, en 1469, Catalina González adquirió las partes que poseia en Gironda a Isabel García, mujer de Juan de las Cabezas, su cuñado, ya difunto. En 1513 García de Tapia recupera la parte perteneciente a María Jiménez, su tía segunda, heredada por Maria de Aguilar, quien se la vende a aquél.

Por esta razón la propiedad de Gironda se convierte en el solar y en el núcleo central del mayorazgo de los Tapia. La historia de esta heredad nos ilustra la política seguida por esta familia antes de la creación de su vínculo en 1561, como fórmula y método - utilizados por la noblezapara mantener sus propiedades. Entre 1463 y 1547, los Tapia recurrieron para mitigar el proceso de inestabilidad y movilidad de sus bienes a unas meditadas alianzas matrimoniales y a un constante desembolso de dinero para comprar nuevas tierras que paliaran la dispersión de las propiedades y favorecieran su concentración. Se producía, pues, en cada generación un fenómeno de acumulación, división y vuelta a acumular de nuevo (50). Proceso que se interrumpe con la fundación del vinculo, ya que una parte considerable del patrimonio se hace inalienable y transmisible por herencia en orden de primogenitura (51).

Pero la documentación no sólo nos informa de la estructura familiar de un linaje y de la composición de sus bienes, también nos describe el paisaje. En los inventarios se reseñan tres heredades o dehesas. Las tres poseen casas, casares, palacios, cercas, cortinales, corrales, tierras de pan llevar, pastos, abrevaderos, establos, pozos, caballerizas, huertos, colgadizos, pajares, hornos, gallineros y ejidos (52). Gironda aparece además con una torre y un molino. La viña de La Planta en Santa Cruz de la Sierra tenía casas, lagar y bodega. Todas las propiedades estaban en localidades del término de Trujillo: Garciaz, Santa Cruz de la Sierra, calificados de lugares, y en las aldeas de Gironda y Torrecilla. 


\section{NOTAS}

(1) Está formado por 22 legajos.

(2) Juana Tadeo de Orellana y Tapia contrajo matrimonio en Jerez de la Frontera con Diego Zurita y Auñón en 1654.

(3) Clodoaldo NARANJO ALONSO, Trujillo y su tierra. Historia, monumentos e hijos ilustres, Trujillo, 1922, t. I, p. 432.

(4) Emilio CABRERA MUÑOS, El condado de Belalcázar (1448-1518), Córdoba, 1977, p. 344.

(5) (A)rchivo de la (M)arquesa de (C)ampo (R)eal de (J)erez de la Frontera. Vínculo de Alonso de Tapia Altamirano, leg. $3, \mathrm{~N} .^{\circ} 4$.

(6) En 1540 las ermitas citadas en el testamento de María Altamirano eran cuatro: Nuestra Señora de la Piedad, La Magdalena, Los Mártires y San Lorenzo.

(7) A.M.C.R.J., Vínculo de Alonso de Tapia Altamirano, leg. 3, N. ${ }^{\circ} 5$.

(8) Ibidem.

(9) Ibid., leg. $3, \mathrm{~N} .{ }^{\circ} 1$.

(10) Ibid., leg. $3, N^{\circ} 3$.

(11) Ibid., leg. $3, N^{\circ} 2$.

(12) Ibid., leg. $3, \mathrm{~N}^{\circ} 7$.

(13) Ibid., leg. $3, N .{ }^{\circ} 8$.

(14) Ibid., leg. 3, N. ${ }^{\circ} 9$. Nombra herederos a los hijos de Francisca de las Cabezas en el caso que su hija Teresa muriera sin testar; circunstancia que ocurrió.

(15) Ibid., leg. $3, N^{\circ} 17$.

(16) Ibid., leg. $3, \mathbf{N} .^{\circ} 18$. Son citados como testigos: Juan de Trujillo, criado de Juan de Tapia, Pascual y Pedro, pastores serranos, vecinos de Torrevielo, tierra de Sepúlveda.

(17) Ibid., leg. 3, N. ${ }^{\circ} 10$.

(18) Ib/d., leg. $3, N .{ }^{\circ} 6$.

(19) ibid., leg. $3, N^{\circ} 13$

(20) Ibid., leg. $3, N^{\circ}{ }^{\circ}$. Ordena dar a su criado, Andrés Barba, 1.000 maravedíes y vestidos.

(21) Ibid., leg. $3, N^{\circ} 12$.

(22) Ibid., leg. $3, \mathrm{~N} .{ }^{\circ} 14$.

(23) Ibid., leg. $3, \mathrm{~N} .{ }^{\circ} 11$.

(24) Ibid., leg. $3, \mathrm{~N} .{ }^{\circ} 15$.

(25) Ibid., leg. $3, \mathrm{~N} .{ }^{\circ} 20$. Alonso de Tapia muere entre el 22 de agosto y el 13 de septiembre de 1489, fecha de la redacción de su testamento por su madre, Francisca de las Cabezas y Pedro Gallego. Estaba casado con Teresa González, embarazada en el momento de su fallecimiento. El matrimonio tenía una hija, Maria de Tapia. Entre las mandas testamentarias incluye la voluntad de que sean vestidos cuatro pobres: Juan de Alcántara, criado de su abuelo, Alonso de Tapia, y de su padre, Gómez de Tapia; Juan Castro, criado de García González de Gironda, de Santa Cruz de la Sierra y criada de su abuelo, Alonso de Tapia, y Teresa de Tapia criada también del anterior. Todos serían vestidos de paño burel a sesenta maravedís la vara. En otra cláusula se estipula que si el descendiente es varón, se llame Gómez de Tapia, y herede la tercia parte de todos los bienes, además de su legítima. Requisitos que se cumplieron más tarde. Sin embargo, el mismo testamento especificaba que en el caso de nacer una niña, las dos hijas entonces heredaran igualmente el $50 \%$. 
(26) Ibid., leg. $3, \mathrm{~N} .^{\circ} 19$.

(27) La heredad fue dividida en 11 partes. A Juan de Tapia le correspondio 9.

(28) Le correspondía dos partes.

(29) La heredad de Gironda fue dividida en 5 partes. De ellas, cuatro partes y media eran para García de Tapia y Gómez de Tapia. De la media parte restante se hicieron cuatro partes, de las cuales tres fueron para Juan de Tapia y la otra cuarta se volvió a dividir en cinco partes de las que tres pasaron a García de Tapia y Gómez de Tapia y las dos restantes a Juan de Tapia.

(30) Con la obligación de pagar 500 maravedíes de ellos a la capellanía fundada por su madre, Francisca de las Cabezas.

(31) Ut supra, cita 29.

(32) Recibió la cuarta parte del alcaçer e cerca que está a la carrera.

(33) Recibió la mytad de la cerca que esté cave la carrera.

(34) A.M.C.R.J. Vínculo de Alonso de Tapia Altamirano, leg. 3, N. ${ }^{\circ} 21$.

(35) Ibid., leg. 3, N. ${ }^{\circ} 23$.

(36) Ibid., leg. $3, N^{\circ} 27$. María Jiménez era de García de Tapia.

(37) lbid., leg. $3, N^{\circ} 27$.

(38) Ibid., leg. 3, N. 24.

(39) Ibid., leg. 3, N. ${ }^{\circ} 22$.

(40) Ibid., leg. 3, N. 25.

(41) Ibid., leg. $3, \mathrm{~N}^{\circ} 29$.

(42) Ibíd., leg. $3, N^{\circ}{ }^{\circ}$ 30. La abadesa era Estefanía de Paredes, y Romera Alonso, vicaria. Las 8 monjas profesas que aparecen en el capitulo eran María de Alvarado, Isabel Grajateras, Juana Gonzáleź de Torres, María Altamirano, Catalina de Carvajal, Elvira Cabeza, Francisca de Loaisa y Violante Caiderón.

(43) Ibid., leg. $3, \mathrm{~N}^{\circ} 26$.

(44) Ibid., leg. $3, N^{\circ} 28$.

(45) Ibid., leg. $3, N^{\circ} 31$.

(46) Ibid., leg. $3, N{ }^{\circ} 33$. A Maria, su criada, le den al momento de casarse una cama de ropa con un colchón y dos sábanas.

(47) Ibid., leg. $3, N^{\circ} 33$.

(48) lbid., leg. $3, N^{\circ} 32$.

(49) Ibid., leg. 4, N. ${ }^{\circ} 42$. Actualmente sólo se conserva un extracto del documento en el Protocolo del Caudal del marqués de Campo Real en Truxillo de 18 , fol. $62 r^{\circ}-64$ v. ${ }^{\circ}$

(50) Es un proceso similar al expuesto, aunque referido a un espacio y una época diferentes, por Antonio Miguel BERNAL en Economia y sociedad en Andalucía durante el fin del Antiguo Régimen y la revolución burguesa. "Aproximación a la Historia de Andalucía", Málaga, 1978, p. 195-214.

(51) Bartolomé CLAVERO, Mayorazgo. Propiedad feudal en Castilla en 1369-1836, Madrid, 1974, p. 265.

(52) J. L. MARTIN GALINDO, La dehesa extremeña como tipo de explotación agraria. "Estudios Geográficos", N. 103 (1966), p. 157-226. 